\title{
La política posible en la imposibilidad de lo político. Apuntes para una lectura de H. A. Murena*
}

Fecha de entrega: 7 de diciembre de 2016

Fecha de evaluación: 16 de febrero de 2017

Fecha de aprobación: 20 de abril de 2017

\section{Lucas Oro Hershtein**}

\section{Resumen}

Este trabajo se propone reflexionar, a partir de la obra de H. A. Murena, sobre el 'sentido' de lo político en América. A partir de categorías teóricas del autor, busca preguntarse si es posible construir una práctica política propia que no se resigne a definir el sentido desde el pasado americano o desde lo europeo. América es la tierra donde la ausencia de un origen petrificado permite a sus habitantes crear una comunidad auténtica. Es gracias a dicha ausencia que los americanos no precisamos poner entre paréntesis la ontología para dar paso a la ética, ya que la comprensión del origen como ausencia impide operar a la lógica metafísica que reduce el tiempo a la presencia.

Palabras clave: la política, lo político, Murena, sentido.

* Artículo de investigación. DOI: http://dx.doi.org/10.15332/s0120-8462.2017.0117.02

* Licenciado en Filosofía (Universidad de Buenos Aires). Estudiante del Doctorado en Filosofía (Universidad de Buenos Aires) y becario doctoral (Conicet). Ha sido becario de la Asociación Universitaria Iberoamericana de Postgrado (AUIP) en la Cordoba Near Eastern Research Unit (CNERU) de la Universidad de Córdoba (septiembre del 2015), becario en la École des Hautes Études Hispaniques et lbériques (ЕHEHI) de la Casa de Velázquez (marzo a mayo del 2016) y becario del Proyecto "Practicing Knowledge in Islamic Societies and their Neighbours" (Anneliese Maier Research Award, Humboldt Foundation) dirigido por la Prof. Maribel Fierro en la Munich School of Ancient Philosophy de la Imu München (junio a agosto del 2016), el Seminar für Arabistik/Islamwissenschaft de la Georg-August-Universität Göttingen (septiembre a noviembre del 2017) y el Instituto de Lenguas y Culturas del Mediterráneo y Oriente Próximo del cchs-csic (diciembre del 2017). I.oro.hershtein@gmail.com 
The possible policy in the impossibility of the political. Notes for a reading of H. A. Murena

\section{Lucas Oro Hershtein}

\section{Abstract}

This work intends to reflect, from the work of H. A. Murena, on the 'meaning' of the political in America. Based on the author's theoretical categories, he seeks to ask himself if it is possible to build a political practice of its own that does not resign itself to define the meaning from the American past or from the European past. America is the land where the absence of a petrified origin allows its inhabitants to create an authentic community. It is thanks to this absence that Americans do not need to put ontology in parentheses to make way for ethics, since the understanding of the origin as absence prevents the metaphysical logic from operating which reduces time to presence.

Keywords: politics, the political, Murena, meaning.

\section{A política possivel na impossibilidade do político. Notas para uma leitura do $\mathrm{H}$. A. Murena}

\section{Lucas Oro Hershtein}

\section{Resumo}

Este trabalho se propõe refletir, a partir da obra do H. A. Murena, sobre o "sentido" do político na América. A partir de categorias teóricas do autor, busca se perguntar se é possível construir uma pratica política própria que não se resigne a definir o sentido desde o passado 
americano ou desde o europeu. América é a terra onde a ausência de uma origem petrificada permite a seus habitantes criar uma comunidade autentica. É graças a esta ausência que os americanos não precisamos colocar entre aspas a ontologia para abrir espaço à ética, dado que a compreensão da origem como ausência impede operar à lógica metafísica que reduz o tempo à presença.

Palavras-chave: a política, o político, Murena, sentido.

\title{
Lo extranjero
}

Existe una cierta relación entre el modo en que un escritor presenta su narrativa y el camino por el que un lector atraviesa la obra. En su opúsculo Agua viva, C. Lispector (2008) afirma:

\begin{abstract}
Veo que nunca te he dicho cómo escucho música: apoyo levemente la mano en el fonógrafo y la mano vibra y transmite ondas a todo el cuerpo: así oigo la electricidad de la vibración, sustrato último en el dominio de la realidad, y el mundo tiembla en mis manos. (p. 13)
\end{abstract}

Cuando H. A. Murena abre su texto La metáfora y lo sagrado con la imagen de la recitación del Corán, realiza un movimiento similar: nos invita a 'oír' su texto. Sin embargo, nos invita a oír un texto que no se recita, sino que se entrega al destinatario - es decir, a nosotros mismos- con la forma de la escritura. Entonces, ¿cómo podríamos oírlo?

Desde Heráclito - y su célebre fragmento, "Los ojos son testigos más exactos que los oídos" (B 101 a) - la filosofía privilegia, sobre el sentido del oído, el sentido de la vista. La subordinación del oído a la vista corresponde a la superioridad otorgada a la voluntad del hombre en el reino de lo existente. La vista distingue y escoge qué ver: opta por ver aquello y desconocer lo otro. Por el contrario, el oído carece de semejante poder. En cuanto nuestros oídos despiertan, no podemos evitar oír. El sentido de la audición es la muestra más cabal de la excedencia del ser respecto del pensar, porque al escuchar constatamos que el ser excede aquello sobre lo cual los sentidos pueden disponer. Podemos pensar sobre lo que hemos oído, pero no podemos negar - suprimir o demostrar- aquello desde cuya realidad pensamos. 
Cuando Murena comienza su texto con el recitado del Corán, nos propone acercarnos a sus palabras no desde la soberbia del ver, sino desde la humildad del oír. 'Oír' el texto de Murena implica cumplir con el dictado de H.-G. Gadamer (1998): "el que oye algo, oye con eso aún algo más, es decir, también lo invisible, y todo lo que se puede pensar" (p. 48). Los textos de Murena resultan ser una audición. Murena escribe tal como Clarice Lispector escuchaba. Escribe invitándonos a poner la mano sobre la obra y sentir su vibración. Así, como en aquella tan célebre fotografía de Alejandra Pizarnik en la cual la poetisa acomoda una serie de figuras de papel sobre la acera, Murena (2002a) recorta desde el silencio sus propias 'figuras', a las que transforma en palabras: "las figuras que un artista forja expresan a la vez en la forma más secreta y más clara los términos decisivos del problema que su existencia afronta” (p. 227).

Al proponernos escuchar un texto escrito, Murena nos invita a la diseminación del sentido. Con ello, acomete su propio embate intelectual contra el modelo binario del pensamiento occidental, solo que extendiendo su zona de validez. Para Murena (2002a), 'Occidente' no es solo un lugar concreto en la geografía mundial, sino un modo de pensamiento (p. 223). Es el modo de pensamiento en el que, como en el Occidente geográfico, el sol cae y el día comienza a declinar, donde habita

[el] hombre que ha perdido el contacto, [y que entonces] sin tacto para muchas cosas que antes percibía, [ahora] trueca la reflexión espiritual por la acción: vuelca el intelecto hacia la superación práctica de los obstáculos externos, arrancándolo de su tarea interna de construcción del hombre. Es el espíritu de Occidente que se exacerba hasta hoy, convertido en espíritu mundial. (Murena, 1969, p. 10)

Así, el "logocentrismo" (Derrida, 2009) ya no es una acusación dirigida exclusivamente al privilegio concedido a la voz frente a la escritura, sino que se extiende a la propia escritura. Solo la audición en la lectura permite habitar el pensamiento más allá de la reificación que según Murena carcome, en nuestros tiempos, a toda reflexión. Como él afirma (2002a), "la velocidad con que el existencialismo ha sido corroído como herramienta del pensar indica la excepcional capacidad reificante del ámbito mundial contemporáneo. Todo aquello que se formula - esto es, que se convierte en espíritu- queda ipso facto muerto" (p. 353). El procedimiento de Murena -la audición de lo que está escrito, en el acto mismo de su lectura- atiende a la realidad de la diseminación del origen que él se preocupa por comprender. La relación 
entre la realidad y su descripción es la misma que se encuentra en Martínez Estrada (1958), cuando afirma:

Todo lo que realmente acontece se cumple conforme al lenguaje del mito, porque es mito puro [...] y entonces nada más sensato que expresar hasta donde hoy sea posible (dentro de la red de ficciones en que nos hemos capturado) esa realidad en su connotación lógica: el mito y la alegoría. (p. 35)

En ese sentido, el método de Murena podría ser entendido como fenomenológico:

Lo que caracteriza a dicho pensamiento [fenomenológico] es que en vista de la extrema cuestionabilidad de lo más extremo, [el pensamiento] no se rige precisamente por la regla del principio de no contradicción, sino que deja que se dé en su pureza lo que se muestra; es decir, asume su carácter paradójico [...] [y] se sustrae al pensamiento toda captación definitiva. El pensamiento sólo puede mantenerse en el puro gesto del "estar-atento-a" lo que a él le es manifiesto y que al mismo tiempo sigue siendo enigmático. (Casper, 2000, pp. 114-115)

Los textos de Murena son cual los pequeños hombrecitos de papel de Pizarnik: un desordenado recorte de figuras musicales que invitan a detenerse, no solo en ellos mismos, sino en todo lo invisible que, aunque no podamos ver, sabemos -oímosque los rodea, los señala y los protege.

\section{Los hombres}

El ensayo La cárcel de la mente se abre con la siguiente afirmación: "El primero de los enigmas que ha de golpear a un americano es su lugar de nacimiento" (Murena, 2002a, p. 223). El mundo mureniano es un mundo de enigmas; y el mayor peligro que amenaza al hombre es el de la totalización del saber y de la realidad. Tal es la amenaza que intenta constantemente conjurar Murena. Por eso, los enigmas murenianos no son acertijos. Su 'verdad' se desplaza constantemente, tanto como la 'verdad' de la realidad que reflejan. Un enigma que pudiera resolverse ya no tendría nada que decir acerca del mundo. Si el procedimiento metodológico utilizado para conocer la realidad es, en Murena, fenomenológico, también lo es su definición del hombre: 
El hombre es esa extrañísima criatura que no tiene un ser dado y cerrado a todo de antemano, como la piedra, como el animal que vive en el éxtasis de sus propios seres conclusos, sino sólo un ser posible, recién iniciado, que debe hacerse él mismo. Ni el ser acabado de la piedra ni el no ser: el hombre es necesidad de ser, sentimiento de lo que le falta para ser, angustioso sentimiento de desposesión en medio de un extraño mundo. (Murena, 2002a, p. 252)

Tan 'extraño' como el hombre y el mundo es la 'figura' del pensamiento que Murena denomina 'origen'. El origen es 'extraño' para el mundo — pues no se identifica con él; ni con el mundo como 'tierra' ni con el mundo como 'orden'- y para el hombre, pues no es pasado ni es futuro. Ambas alternativas - ser pasado o ser futurocondenan el origen a ser una presencia. Sin embargo, el origen es, en Murena, una 'praes-entia' - en el sentido dado por praesens en tanto participio presente activo del verbo latino praesum; es decir, un desplazamiento hacia el presente. El origen no es un punto referencial en el pasado ni una meta abstracta colocada en el futuro; pero tampoco es la distancia entre dichos puntos y nuestro instante presente, puesto que, como dice Murena (2002b), "nunca la distancia logra presentarse en su entera pureza” (p. 450). Es decir; el origen es no solo extraño - ajeno- para el mundo y para el hombre, sino también con respecto a sí mismo.

El origen, en otras palabras, debe ser creado por aquel de quien es origen. Esa creación no parte desde la absoluta carencia - aunque no lo haga tampoco desde un lugar definido. El hombre que recrea el origen es, en palabras de J.-L. Nancy (2003), una “'finitud' [que] nombra esa afección esencial que ek-siste la esencia” (p. 57). Ahora bien, "finitud debe decirse de lo que carga con su fin como si le fuera propio". El hombre debe cargar con su origen — que es también su fin, puesto que está inventándolo- 'como si' le fuera propio, ya que lo es solo en el instante en que lo actualiza, viviéndolo, para luego volver a dejarlo perderse en el infinito.

El origen del hombre no es su 'propio' origen, porque el origen no es una 'presencia' -y solo una presencia puede ser 'a-propiada'. Paradójicamente, el origen solo está presente porque no está presente; o, en otros términos, porque no es una presencia. Si el origen fuera ora una presencia - como pasado, presente o futuro- ora una ausencia radical, no cabría la posibilidad de 'ser traído a' la presencia. El origen no es presencia ni es ausencia, sino una herida abierta en el presente por una no presencia. Esa no presencia - y con ella, la temporalidad del origen- escapa al tiempo. 
El parricidio que se invoca como necesario para la vida y el pensamiento genuinos es, entonces, la liberación de un fantasma, de una presencia espectral que nos acosa. Murena (2006) escribe:

En los mundos antiguos hay un padre que guía en estos primeros pasos graves, que protege contra la crudeza del mundo, que mitiga esa sensación de desposeimiento. Ese padre es la historia. Los mundos antiguos están encubiertos por un manto de sentido que generaciones y generaciones de seres humanos les han ido inculcando, son menos mundo en el sentido en que el mundo es hostil, en que le falta al hombre para ser. En cada aldea, en cada campo, en cada ciudad [...] todo se entrelaza para formar un abrigo dulce y poderoso, la historia, en suma, una sombra paterna a cuyo amparo se puede aprender sin angustias a amar un oficio, una mujer, la tierra. [...] Ese es nuestro secreto de americanos, la herida por la que gotea lenta y dolorosamente, por la que se nos va nuestra vida: no tenemos historia, no tenemos padre. (pp. 96-97)

El asesinato de la espectral presencia del padre es una rememoración constante:

La vida del hombre es metafórica. [...] Volver a hablar en verso, igual que en el Paraíso, representa la capacidad de recordar en forma activa la Ausencia: no buscarla en el pasado ni esperarla para el futuro, sino hacer vivir el recuerdo en nuestro instante presente. (Murena, 2002b, p. 446)

Solo un hijo sin padre - un fragmento sin el todo, el exiliado de una diáspora sin centro de retorno- puede traer el origen a la presencia. La ausencia mureniana es un "secreto" (Murena, 2002b, p. 252); o, tal vez, el secreto no es la ausencia misma, sino su propio recuerdo. Todos nosotros - los americanos, los hombres- guardamos el secreto del recuerdo de una ausencia. Ese secreto es, pues, la huella de una huella. En forma de ausencia, guardamos la presencia de su propia ausencia. El origen mureniano podría, en su indescriptibilidad, ser convocado por J. Derrida (2005), quien afirma:

[Existe] un pasado, un allí-desde-siempre al que ninguna reactivación del origen podría dominar plenamente y despertar a la presencia. Esta imposibilidad de reanimar absolutamente la evidencia de una presencia originaria nos remite entonces a un pasado absoluto. Esto es lo que nos autoriza a llamar huella a aquello que no se deja asumir en la simplicidad de un presente [...]. Si la 
huella remite a un pasado absoluto es porque nos obliga a pensar un pasado que sólo puede comprenderse en la forma de la presencia modificada, como un presente-pasado. (p. 86)

La reflexión de Murena se torna apasionante cuando nos percatamos de que el secreto no es solo un no-objeto conservado, sino la trama de nuestra propia existencia:

[La ausencia no es] de índole sociológica, sino ontológica, pues no se refiere a una accidental situación por la que atraviesa una comunidad, sino a una instancia de ser o no ser, a un problema de vida o muerte. (Murena, 2002a, p. 258)

Si la ontología del hombre es metafórica, es porque "la metáfora [...] procura decir lo indecible: el silencio" (Murena, 2002b, p. 436). La vida del hombre - así como "la música es la historia de los intentos por reconstruir el silencio puro sacro"- es el intento de reconstruir el desgajado recuerdo del silencio. El hombre pasa las cuentas de su secreto, una a una, como quien recorre lenta y pausadamente el rosario. Una y otra vez: sin terminar nunca, sin empezar nunca. Tal intento solo puede ser en verso - en la existencia cotidiana devenida verso- porque, tal como la metáfora disemina el significante - hasta hacer estallar el significado-, el hombre disemina el sentido del origen. Sin embargo, dicha diseminación consuma el origen mismo. 'Origin-ando', el hombre lleva a su fin el carácter no temporal del origen, transformando una ausencia en la posibilidad de una presencia: el don.

El acto del origen, el origen en verbo, es la forma de escapar del peligro del origen. Incluso siendo el origen un secreto cuyo contenido nunca coincide consigo mismo, el hombre puede caer en la tentación de revelar dicho secreto. Hacerlo - revelar el secreto de los secretos- es hundir todas nuestras posibilidades en la nulidad de la totalización. Si revelamos el origen - la marca de la ausencia-, perdemos toda posibilidad de tener un origen, porque dejamos escapar cualquier posibilidad de ponerlo en movimiento, de hacer algo con él. Por dicha posibilidad, por tener dicha posibilidad que nos lleva a vivir "en el límite" (Murena, 2002a, p. 305) del precipicio que separa la apertura total y la autocondena absoluta, el hombre americano es el único que no vive aún -o no vive enteramente- en "una sociedad que va siendo progresivamente abierta, privada de interioridad, convertida en pura exterioridad" (Murena, 2002a, p. 358). 
Como Murena afirma, "vivir es aceptar la enfermedad" (Murena, 2002a, p. 261). Por eso, es preciso optar por no revelar ni olvidar — dos gestos paralelos- nuestro secreto, para traer el origen al presente, transformándolo en don. Operando con el origen, verbalizándolo como don, vivimos - como dice Murena- en el "tajo en la malla de la historia" (Murena, 2002a, p. 234). O, en otras palabras: "hay que asumir conciencia de lo negativo y colocarse en el único lugar posible para entablar la lucha: en el límite" (Murena, 1961, p. 107).

\section{La tierra}

Según Murena (2002a), la principal característica de nuestra sociedad es el "primado de lo cotidiano":

Esta humanidad entregada a lo habitual, esta humanidad reducida progresivamente a lo consabido - paradójicamente, es un mundo lleno como nunca de 'novedades'-, esta humanidad que aspira y espira cotidianeidad, esta humanidad que ha renunciado a la acción o a la idea extraordinaria y que cuando incurre en ellas se apresura a disfrazarlas de comunes y vulgares... (p. 361)

El mundo se ha convertido en el desierto de lo habitual y, para Murena (2002a), "en lo habitual no se entrega ni se recibe nada" (p. 364). La ausencia de don es causa y consecuencia de la atrofia de una sociedad que no llega a convertirse en comunidad, y de una comunidad que no llega a entrar en comunión: "cuando se vive lo habitual, se es todos - porque lo cotidiano es igual, común-y nadie" (Murena, 2002a, p. 363).

Ahora bien, esa realidad no resulta de la opresión de unos hombres sobre otros. Por el contrario, Murena (2002a) se pregunta:

¿Cuál es entonces el poder que presiona hoy sobre la humanidad hasta lograr que la vida que piensa, i.e., la vida humana, se retraiga a la nulificación de lo habitual? Ese poder consiste en una sociedad que marcha rumbo a una totalización tal que ya no necesitará ser totalitaria [es decir, que ya no necesitará de totalitarios]. (p. 358) 
Si bien "lo habitual [...] torna imposible lo insólito" (Murena, 2002a, p. 358), lo insólito sigue - en este tiempo- presente. La condición de su presencia — de su presencia como posibilidad - es que nuestra sociedad no ha sido completamente totalizada. En la base de nuestra América se encuentra el secreto que la constituye -el secreto que es su nombre oculto y que forma la huella, en el tiempo actual, de la ausencia primigenia abstracta que garantiza que su círculo temporal no se cierre-. Allí, en la sociedad de lo abierto donde todo ha sido revelado, donde nada está oculto, no hay nada que un hombre pueda entregarle a otro, puesto que todo 'ya' está - en sentido ontológico, no temporal- dado. En la sociedad de lo habitual, no hay ni puede haber don, y la política solo es la administración de 'lo mismo' para 'nadie'.

Una sociedad de nadies no es una comunidad. Por el contrario, "la vida humana es capacidad de eco [...] [y] vivencia de lo otro" (Murena, 2002a, p. 358). En una sociedad de 'nadies', solo hay soledad. No la soledad de los desiertos, no la distancia, sino aquella otra soledad de la proximidad extrema. La soledad de la masificación, la que impide contemplar al otro y escucharlo como tal, más allá de mí mismo.

Sin embargo, el secreto que América guarda la protege. La protege sin que la propia América lo sepa, puesto que ha olvidado que guarda - aunque lo central es el acto y no el contenido- un secreto. Ese secreto es el origen, el origen que - más allá de la dicotomía entre la presencia y la ausencia- hace su aparición en el presente. Por esa herida sin tiempo, por ese "misterio" (Murena, 2002, p. 436), América no es aún un mundo completamente abierto.

Así como Murena (2002b) afirma que "el arte nace por necesidad de Dios" (p. 436), podría decirse que el don nace por necesidad del origen. Como escribe Blanchot (1990), "el silencio es imposible. Por eso lo deseamos" (p. 17). El don es el signo -el vestigio- de una ausencia que no puede ser traída a la presencia. El origen rompe la habitualidad - y al hacerlo hace estallar la totalidad de la sociedad abierta - no por la referencia al pasado, sino mediante la iterabilidad. El origen en cuanto pasado remite al origen en tanto presente, y a la inversa. Esa iterabilidad es la muestra más cabal de que el hombre, hablando y viviendo - lo que quizá sea lo mismo - en verso, funda una comunidad rota. Solo en esa comunidad eternamente desplazada de sí misma, imposible de totalizar - porque su iterabilidad la condena a ser siempre diferente de aquello que ahora mismo es-, se hace posible el don. El don es posible solo allí donde no hay totalidad, donde la comunidad no es 'una', porque no hay un origen que la determine. Pero, a la vez, es el don el que logra fundar — abriendo una grieta- esa 
comunidad, desgarrando el tiempo. Solo la no inmanencia de la comunidad permite, paradójicamente, la inmanencia de la comunidad. Vale la pena aquí citar a Blanchot (2002), quien afirma:

Si el comunismo dice que la igualdad es su fundamento y que no hay comunidad en cuanto las necesidades de todos los hombres no estén igualmente satisfechas (exigencia en sí misma mínima), supone, no una sociedad perfecta, sino el principio de una humanidad transparente, producida esencialmente por ella sola, 'inmanente' (dice Jean-Luc Nancy): inmanencia del hombre al hombre, lo que designa también al hombre como el ser absolutamente inmanente, puesto que es o debe llegar a ser tal que sea enteramente obra, su obra, y finalmente, la obra de todo; no hay nada que no deba ser formado por él, dice Herder: desde la humanidad hasta la naturaleza (y hasta Dios). Nada de restos, en último término. Es el origen aparentemente sano del totalitarismo más malsano. (pp. 11-12)

Esa herida en la totalidad no resulta - no se desprende - de dicha totalidad, sino que la constituye intrínsecamente; la constituye en tanto totalidad no concluida, en tanto comunidad rota. Por eso, esa herida — es decir, el origen - en Murena (2002a) es, utilizando dos términos del autor, el "resto" o lo "residual" que impide el cierre de la totalidad (p. 403). Sin embargo, el origen no es solo la herida en la malla de la historia. No es solo un espacio, sino que es la zona donde resuenan, en palabras de J.-L. Marion (1989), un llamado y su sorpresa (pp. 300 y ss.).

Como se ha mencionado, es posible anular un secreto revelándolo u olvidándolo. Por eso Murena (2002a) afirma que "la única forma de superar la negación es ejecutarla hasta el fin” (p. 244). Ejecutar la negación implica consumarla. El origen se consuma en el don. A la pregunta de Murena (2002b) que el autor se realiza en uno de sus ensayos, “¿Cómo se hace posible la imposible vida humana?” (p. 448), podría responderse con otra frase del mismo texto: "la poesía redime el pecado, aceptándolo" (p. 438). En otras palabras: el don redime el origen, aceptándolo.

Redimir el origen aceptándolo es, precisamente, aceptar el llamado del origen sin pretender resolver su enigma. Redimir el origen sin saturarlo es escapar de la "sistematización" de Babel, permaneciendo en la "diferencia" eterna en la cual las contradicciones se pliegan (Murena, 2006, p. 216). 


\section{La política posible}

Existe una diferencia entre 'lo político’ y 'la política’ señalada por R. Beardsworth (2008):

El término 'política’ designa el dominio o la práctica de la conducta humana que normativiza las relaciones entre un sujeto y sus otros (otros sujetos humanos, la naturaleza, la técnica o lo divino). Considero que el término 'lo político' es la instancia que reúne o funda dicha práctica como una práctica. (p. 15)

La ausencia de origen es una llamada que convierte la política en una exigencia, pero, a la vez, torna imposible lo político, en tanto se "exige un fundamento real: la historia, la existencia [...] [y] en realidad, América no tiene historia propia” (Murena, 2006, p. 211). Desde la ausencia de un origen real se genera una zona de pensamiento delimitada, por un lado, por la espera - imposible de suprimir - de un sentido; y, por otro lado, por el saberse más allá de la espera y la demanda de un sentido. Ambas realidades nos advierten que América - como 'mundus' - ha dejado de existir, al sustraerse a todo régimen posible de significación.

El sentido es, siempre, una referencia a algún afuera, a algún 'otra parte', de aquello de lo que es sentido. Buscar un sentido para América es tener el sentimiento de que el significado 'América' solo puede tener por significante a otra cosa: a la antigua América o a Europa (Murena, 2006, p. 37). Por el contrario, América no tiene ya un sentido; pero este es, precisamente, el sentido de América. El 'sentido' de América no se obtiene a partir del reenvío de una significación.

"El fin del mundo del sentido abre la praxis del sentido del mundo", afirma J.-L. Nancy (2003, p. 24). El fin de la significación de América a través del reenvío de dicha significación a un otro de América, abre la posibilidad de apostar a transformar el sentido mismo de lo que América es. Podríamos parafrasear a E. Levinas (2006) cuando se pregunta "¿las significaciones no requieren un sentido único al cual pedirían prestada su significancia misma?” (p. 45), afirmando que el sentido de América excede a sus significaciones.

Para re-crear el sentido de América, no es necesario realizar una 'epoché' del sentido que América ahora mismo tiene. El sentido, entendido como una referencia a una otredad que explica aquello que es significado, tiene en América un doble rol. Por un 
lado, el rol de la ausencia: es un secreto conservado - ni olvidado ni revelado. Por otro lado, es una ausencia operante: al no haber fundado una totalización histórica, como ocurrió con los orígenes de Europa, el mismo sentido del sentido de América es estar infinitamente suspendido - y abrir, en esa zona de infinito desplazamiento, la posibilidad de ser respondido. En América, la ausencia de sentido es el sentido del sentido, no su modalidad. Por eso, el origen de América es, no un fundamento, sino sorpresa y llamado. Sorpresa, porque es resto: el eterno jaquear a la totalidad. Llamado, porque convoca a su nuevo movimiento, a su nueva apropiación por el don y, entonces, por la política.

J.-L. Nancy (2003) afirma: "la finitud es la verdad, cuyo infinito es el sentido" (p. 55). Nuestra finitud somos nosotros mismos, los americanos; nuestro sentido es el origen; y nuestra verdad es el origen ausente. Por eso, el hombre, cargando con la ausencia del origen 'como si' - 'como si' el origen fuera una 'presencia' y pudiera ser apropiado-, transforma el sentido. Esa transformación le abre al hombre, a su vez, el sentido de la praxis. El recorrido del hombre es, simultáneamente, del sentido sin significación a la praxis y de la praxis al sentido sin significación.

La política logra hacer salir el don de la zona del duelo, del espacio en que se configura solo como un lamento por el origen perdido. La política no logra anular la diseminación del presente sin origen, pero tampoco debe intentarlo. La comunidad auténtica debe, por el contrario, permanecer en el límite en el cual, reconociéndose como imposible, se vuelve posible. Solo una comunidad que asume la imposibilidad de su propia inmanencia - la imposibilidad de su ser comunitario como sujetoforma una comunidad. No es el lugar de la 'soberanía', pero la 'soberanía' no tiene lugar. No existe más que transitoriamente en cada acto comunitario; es decir, en cada acto en que la comunidad deviene comunidad — coincidiendo consigo misma, diferenciándose de sí misma.

Es esta tierra sin origen la que nos impulsa a la política. No somos nosotros los que nos decidimos — nos entregamos- a la búsqueda de un sentido; es el sentido el que viene a nosotros atravesándonos en la urgencia y la necesidad de su llamado. La única política auténtica en una tierra sin origen es una política cuyo sentido sea un sentido sin verdad — es decir, una política no totalitaria-: una política que se abre al sentido, perdiendo la verdad. 
América es la tierra donde la ausencia de origen permite crear una auténtica comunidad. Por dicha ausencia, los americanos no precisamos poner entre paréntesis la ontología, para dar paso a la ética, porque el origen como ausencia imposibilita operar a la lógica metafísica que reduce el tiempo a la presencia. Así, cada 'yo' americano está precedido por un 'otro', porque América es siempre 'otra' de sí misma. Esta relación es anterior hasta el punto en el que el yo no solo reconoce el otro sino que se reconoce en él. El yo se siente cuestionado por el otro. No puede responderle más que con una responsabilidad que no puede limitarse y que se excede, infinitamente, sin agotarse jamás. Al contrario de lo que dice M. Blanchot (2002), cuando afirma que "la comunidad se mantiene en el lugar donde no hay nada que retener" (p. 22), en América la comunidad es posible, precisamente, como no-lugar donde 'hay' nada que retener. En las palabras de J. Derrida (1993), "testimoniamos un secreto sin contenido, sin contenido separable de su experiencia performativa, de su trazar performativo" (p. 67).

La pregunta que, para concluir, es necesario hacerse, dice: ¿podemos, somos capaces de pensar una política de la no autosuficiencia, una política no reducida a la alternativa de las singularidades en suma o la comunidad previa a los singulares? Esta sería la política auténticamente americana, pues sería una política correspondiente a -como Murena exige - una existencia metafórica. A un origen en eterno desplazamiento le corresponde, como lo sostiene Benjamin, una idea de la "historia [como] objeto de una construcción cuyo marco no es el tiempo homogéneo y vacío, sino un ámbito lleno de 'tiempo actual'" (citado en Löwy, 2002, p. 138). Es decir, una política y una fraternidad no-hegeliana - en el sentido de historia, fraternidad y política esbozado en Sartre y Lévy (2006) y desarrollado en Lévy (1984) — sustentada en una diáspora sin exilio —en la ausencia y no en la presencia.

Esta política, extensión y superación no dialéctica del don -en el sentido propuesto por Dussel (1974) - no es una sustancia ni una forma, sino un gesto. El gesto de infinitos gestos - a su vez, infinito cada uno- donde ningún gesto es sustituible por otro, y donde cada gesto existe, realmente, por su exposición a un otro-gesto. El entrelazado de tales gestos puede formar una comunidad donde la libertad política y la libertad filosófica sean la misma libertad (Arendt, 2000, p. 434). En América, donde - como escribió O. Orozco (2000) - lo extranjero no son los hombres sino la propia tierra (pp. 84-85), lo político imposible parece ser, entonces, el único espacio donde la política es posible. 


\section{Referencias}

Arendt, H. (2000). La vida del espíritu. Buenos Aires, Argentina: Paidós.

Beardsworth, R. (2008). Derrida y lo político. Buenos Aires, Argentina: Prometeo.

Blanchot, M. (2002). La comunidad inconfesable. Madrid, España: Editora Nacional.

Casper, B. (2000). “Fenomenalidad trascendental y acaecimiento acaecido”. En Garrido-Maturano, A. (Ed.), La estrella de la esperanza. Introducción a La estrella de la redención de Franz Rosenzweig desde una perspectiva fenomenológica (pp. 111126). Estudios de la Academia Nacional de Ciencias de Buenos Aires, Buenos Aires.

Derrida, J. (1993). Passions. Paris, Francia: Galilée.

Derrida, J. (2005). De la gramatología. D.F., México: Siglo XXI.

Dussel, E. (1974). Método para una filosofía de la liberación. Salamanca, España: Sígueme.

Gadamer, H.G. (1998). “Über das Hören”. En Thomas Voge (Ed.), Über das Hören. Einem Phänomen aufder Spur (pp.197-205). Tübingen, Alemania: Attempto Verlag.

Levinas, E. (2006). El humanismo del otro hombre. D.F., México: Siglo XXI.

Lévy, B. (1984). Le nom de l’homme. Dialogue avec Sartre. París, Francia: Verdier.

Lispector, C. (2008). Agua viva. Madrid, España: Losada.

Löwy, M. (2002). Walter Benjamin. Aviso de incendio. Buenos Aires, Argentina: FCE.

Marion, J.-L. (1989). Réduction et Donation. Paris, Francia: puf.

Martínez Estrada, E. (1958). Muerte y transfiguración del Martín Fierro. Tomo I. D.F., México: fce.

Murena, H. A. (1961). Homo atomicus. Buenos Aires, Argentina: Sur.

Murena, H. A. (1969). El nombre secreto. Caracas, Venezuela: Monte Ávila.

Murena, H. A. (2002a). "La cárcel de la mente”. En Visiones de Babel. DF, México: fce.

Murena, H. A. (2002b). “La metáfora y lo sagrado”. En Visiones de Babel. D.F., México: fce. 
Murena, H. A. (2006). El pecado original de América. Buenos Aires, Argentina: fce.

Nancy, J.-L. (2003). El sentido del mundo. Buenos Aires, Argentina: La marca.

Orozco, O. (2000). Obra poética. Caracas, Venezuela: Ayacucho.

Sartre, J.-P., y Lévy, B. (2006). La esperanza ahora. Las conversaciones de 1980. Madrid, España: Arena. 